\title{
The Language of Loss When a Baby Dies Prior to Birth: Cocreating Human Experience
}

\author{
Christine Jonas-Simpson, RN; $\mathrm{PhD}^{*}$ \\ Director, Nursing Research, Sunnybrook \& Women's College Health Sciences, Centre, Toronto, Canada \\ Eileen McMahon, RN; MN \\ Advanced Practice Nurse, Sunnybrook \& Women's College Health Sciences, Centre, Toronto, Canada
}

\begin{abstract}
When a baby dies prior to birth, a woman and her family begin a life long journey of living and transforming with loss. The language used with families during times of devastating loss is important to reflect upon since, language has the potential to either intensify suffering or enhance the family's experience of grieving. Words that affirm the meaning the baby holds for the family can provide comfort as families engage with the reality of lost hopes and dreams. Recognizing that healthcare professionals do not intend to harm families whose babies die prior to birth, the current authors offer this column as a vehicle for reflecting on the meanings of words used during this particular time of loss and grief. The authors further explore the role that the arts have to play in expressing loss and in helping others to understand.
\end{abstract}

$T_{\text {he }}$ veys many meanings. In titling this paper we wanted to be specific about the language that emerges when a baby dies prior to birth-language that either honors or dishonors the lived experience of loss of a baby. To be consistent with our views of language and meaning we needed to shift from the more common phrase, pregnancy loss, to language that acknowledges women who experience the loss of a baby. In our experience, some mothers living with the loss of a baby at birth have been told by health professionals not to be upset because they lost a pregnancy not a baby, suggesting that a pregnancy is an object void of humanness and void of a sound rationale to grieve the loss. Of course most women do not experience pregnancy as an object. Indeed, the objectification of the baby and the lost pregnancy is a blatant disregard of the reality of the lost baby and this disregard can intensify the suffering of parents. In addition, the objectification of the loss as a lost pregnancy conveys that parents should not speak of the loss as the loss of a child. While much has improved over the past thirty years and perinatal death is no longer a non-event (Leon, 1992), speaking of a baby's death is still taboo in society when the baby dies prior to birth and, in our experience, many parents are still silenced and discouraged from expressing the reality of their grief and sadness.

Language among humans is more than important-it not only expresses personal meaning-language creates mean-

*Authors' Note: The literature search for this column was funded by the Registered Nurses Foundation of Ontario Prenatal and Parenthood Education Services Research Award. ing (Parse, 2002). A broad theoretical concept-called languaging - was created by Parse $(1981,1998)$ in her theory of human becoming. The concept languaging is "expressing valued images" (Parse, 1981, p. 46). Languaging is a concept from the first principle of the human becoming theory. "Structuring meaning multidimensionally is cocreating reality through the languaging of valuing and imaging" (Parse, 1981, p. 42). Languaging is how human beings express meanings about what is important. Expression of meaning happens through speaking-being silent and moving-being still (Parse, 1998). Languaging also tells about the ways people structure their realities and cocreate human experiences. Thus, the words used to describe a baby who dies prior to birth express the meaning of that baby. These meanings can be very different among healthcare professionals, mothers, fathers, and other family members.

The current authors of this column do not believe that healthcare providers intend to harm through the use of language, but we are proposing that harm does happen because of the language used with parents. Indeed, we would like readers to consider the following two questions: What harm or additional suffering is cocreated through language used by health professionals? And, how can language enhance health and quality of care when a family experiences the loss of a baby prior to birth? We hope that this column will enhance awareness of the meanings of the language of loss, and that this awareness may help diminish unnecessary suffering for those who already suffer deeply.

Keywords: baby's death prior to birth, language, languaging, loss 


\section{The Impact of Language}

In the literature it is noted that the biomedical language used by professionals can create further suffering beyond the suffering that is endured with the loss of a precious long awaited baby (Chalmers, 1992; Hutchon, 1998). The potential for unintentional harm is enormous when you consider that estimates show miscarriage occurring in $15 \%$ of clinically recognized pregnancies and the prevalence of miscarriage increases with maternal age from $12 \%$ in woman younger than 20 years of age to greater than $50 \%$ in woman older than 45 years of age (Scott, Gibbs, Karlan, \& Haney, 2003). Moreover, 4.5 million babies are born still each year worldwide, and up to one baby in 100 to 200 are born still in developed countries (International Stillbirth Alliance, 2004). One can only wonder how many babies are miscarried and born still in the developing countries. According to Statistics Canada (2003), in 2001, 2,042 babies were born still after 20 weeks of gestation. What struck one of the authors was that her son was one of these babies and that there were 2,041 other mothers in Canada who experienced the loss of a precious child. Many people are touched by the loss of an infant prior to birth. In fact, most of you reading this column likely know of someone who has been touched by the loss of an infant prior to birth: be it you, a friend, family member, or colleague.

To date the primary focus in the literature on the language of loss prior to birth is focused on a debate about the use of terms such as abortion, missed abortion, spontaneous abortion, incomplete abortion, and habitual aborter as opposed to the use of the terms miscarriage and recurrent miscarriage to describe early spontaneous loss of a baby (Chalmers, 1992; Hutchon, 1998; Pridjian \& Moawad, 1989). Many healthcare professionals are concerned that when the term missed abortion is used to describe spontaneous loss of a wanted child, rather than the term miscarriage, that the term abortion can create further suffering because abortion infers that a choice was made to lose the child. One wonders, does this mean that professionals think that women do not experience loss when a choice is made to have an abortion? There is actually literature on the experience of loss for women who decide to have an abortion (Kolker \& Burke, 1993; Williams, 2001).In order to distinguish between the spontaneous and elective loss of an infant, the terms abortion and missed abortion are being replaced with terms such as first or second trimester intrauterine fetal death (Pridjian \& Moawad, 1989), or delayed or silent miscarriage (Hutchon, 1998). Regardless of the move to sensitize language, Hutchon (1998) found that in two major journals in the United States the term abortion continued to be used up to six times more than other English journals. Interestingly, Hutchon noted that there are no difficulties in French or German as there are two different words for spontaneous loss and elective termination.

Chalmers (1992) addressed a gap in the literature in her commentary regarding the use of terminology in early loss and its meaning to women from different cultures. Chalmers commented that "it is apparent that cultural variations in the meaning of medical terminology may occur and must be recognized by doctors" (p. 357), and we would also include other healthcare professionals in the groups needing to recognize the meaning of terms used with grieving parents. Chalmers recommended, and we concur, that professionals need to explore the meaning of language of loss when a baby dies prior to birth with all mothers and especially those from diverse groups. We also believe that regardless of culture each woman requires sensitivity to meaning when hearing about the loss of her baby.

Chalmers (1992) also suggested that there are additional biomedical terms other than abortion to be concerned about that can cause harm or additional suffering to mothers experiencing loss. Terms such as failed pregnancy, incompetent cervix, inadequate germ plasma, and abnormal chromosomal materialcan also convey harmful meanings. Current authors have listed some of the potentially harmful terms in table one with an example of possible meaning for the person living the experience (see Table 1).

Juxtaposing the medical terms with the possible meanings grounded in human experience clearly brings to light the contrast in meanings. Chalmers (1992) suggested that women may take what medical personnel are using to describe the objective medical situation to describe themselves. It is easy to see how this can happen if a woman is told she is unable to get pregnant or to carry a baby to term because she has hostile mucous or an incompetent cervix. We need to be clear about what we are describing in light of medical situations and diagnoses versus inadvertently inferring a failure of the parents, especially the mother, in that most terms refer to a woman's body failing. Biomedical terms like those listed above which objectify the baby can be hurtful and they can minimize the reality that the baby was probably already loved and anticipated as a unique human being. Objectifying language can minimize the importance of grieving and the importance of the baby, not an object to be discarded, but as a child loved. Some parents feel isolated, misunderstood, and silenced with their grief. Since meanings are cocreated we cannot predict or control how parents assign meaning. It is therefore most important to hear the parent's perspectives on what they are experiencing and feeling.

Gesler (1999) also addressed the power of language in healthcare: "Whether a physician [healthcare professional] uses soothing, neutral or harsh language in a consultation may influence the course of treatment. Medical jargon or medical terms that are not part of a patient's vocabulary can cause anxiety and confusion" (p. 15). We would add that words used by healthcare professionals can linger longer than the course of treatment in that many mothers and fathers whose babies die can recall the day it happened along with every word said or not said to them, and thus our words, for better or for worse, do linger with families who are living with loss. One author recalls the caring and compassion she and her family received from nurses and doctors when her son was born still. Her loss was acknowledged. Her son was af- 
Table 1

Juxtaposing Meanings

\begin{tabular}{|c|c|}
\hline Medical Terms & Possible Meaning Grounded in Human Experience \\
\hline Failed conception & I am a failure, why can everyone else get pregnant? \\
\hline Failed conception due to hostile mucous & It's my fault; how can my baby grow in a hostile environment? \\
\hline Incompetent cervix & I am not competent; I knew something was wrong with me. \\
\hline Products of conception & Was my baby in there or just products? \\
\hline Missed abortion & Did I miss something? \\
\hline Reproductive wastage & My baby isn't garbage. \\
\hline Abortion & I didn't abort my baby. \\
\hline Miscarriage & Did I carry my baby wrong? Or did I miscarry my baby? \\
\hline The dead fetus, or late fetal death & This fetus is the baby of our hopes and dreams. \\
\hline The stillbirth & My baby was born still. My stillborn baby daughter or son. \\
\hline
\end{tabular}

firmed as a human being worthy of grief not an object, a stillbirth, to be dismissed. This way of being among the health professionals has made all the difference to her and her family's ability to live on with their precious loss to this day. Again however, when biomedical terms are used with the intent to describe the medical situation, the meanings assigned by the parents can be very different as evident in Table 1 .

Chalmers (1992) also discussed in her commentary the names of the procedures often conducted after a baby's death which can add additional suffering to grieving parents who view their babies as human beings rather than products of conception. For instance, babies born less than 20 weeks gestation are often disposed of either by sluicing or incineration (Chalmers, 2002). Babies born after 20 weeks are buried and many families hold funerals or special ceremonies for their babies. Gestation, however, does not determine the meaning of this baby to the mother and family, and many families whose babies die prior to 20 weeks may wish to celebrate their baby's life in different ways. Where possible, mementos, such as photographs, footprints, handprints, the blanket used to wrap the baby, or a lock of hair, have been very important to many parents as they may be the only tangible things the parent has to remember their precious child. If healthcare professionals do not see the baby as human, but as a fetus, they will not offer the same mementos that a healthcare provider who believes this child to be a cherished baby will. Language cocreates human experience.

\section{The Consoling-Disturbing Nature of Language}

There is another kind of language used with bereaved parents by healthcare professionals, family, and friends with the intent to comfort and ease the pain. These words try to diminish the loss and thus diminish the suffering. However, attempting to diminish the loss, when the meaning of the loss is significant, is more hurtful and we would suggest potentially harmful. Consider Table 2.

In one study with participants who experienced the loss of their babies between 1965 and 1999 many felt their grief was disenfranchised (Hazen, 2003). Women described what it was like to hear many clichés and one woman stated, "do not tell me that 'Everything's going to be okay.' 'You'll have another baby.' 'God did this for a reason.' All those statements when I was in so much pain did not help me at all' (Hazen, p. 152). Language cocreates human experience. To silence or diminish the loss of a baby in order to diminish the pain of the mother and father can, paradoxically, add additional suffering and pain. Parents who are grieving the loss of their babies wish to have their grief and loss acknowledged as well as the lives of their babies affirmed. The use of clichés is even evident in the popular media.

In a very realistic way, some of the above noted clichés and well-meaning phrases emerged in the popular television drama, $E R$ (Rosato, 2004), when one of the doctors in the show, John Carter, experienced the loss of his baby who was born still. For instance, in the episode where Carter's baby is born still his father reassures him that he can have another one, which is a common response, especially to younger parents. While the intent is to be helpful, his words are not. Having Carter reply with, "I know you want me to feel better Dad, but this baby can't be replaced," could have helped those understand who commonly say, "you can have another one" that these words are not helpful. The storyline has carried on through the new season and we commend the producers for 
Table 2

Words That Are Helpful Or Not

\begin{tabular}{|c|c|}
\hline Not Helpful/Potentially Harmful & Helpful \\
\hline You can have another one. & I don't know what to say. \\
\hline It was for the best, he might have had brain damage. & I am sorry. \\
\hline This part of your life is over. You need to move on. & I can't imagine what this must be like for you. \\
\hline Lucky you have other children at home. & I am so sorry for your loss. \\
\hline At least you didn't know him/her. & Did you name your baby? What is her/his name? What does s/he mean to you? \\
\hline God needs angel babies too. & What is this like for you? \\
\hline Did the funeral bring closure? & What did the funeral mean to you? \\
\hline Time heals all wounds. & How will you get through this? What will help you now? \\
\hline
\end{tabular}

sharing this painful experience with the world; the portrayal may help others understand what many parents experience and thus the way others are with them.

\section{Do Healthcare Professionals Fear Death?}

Healthcare professionals use biomedical language to differentiate diagnoses and to pass information from one to another. Objectifying language may also be used by healthcare professionals to distance themselves from the pain and reality that an infant has died. Fear of death among healthcare professionals can lead to a disconnect with mothers and families. This fear requires exploration because it shapes the way the professional will speak, and be silent, as well as how the professional moves and stays still with the families involved.

Some healthcare professionals do not believe a fetus is a baby or an infant and this belief will be revealed in his or her language and actions. What is important here, however, is honoring the meaning of the baby to the parents even when it may be different from the healthcare professional's meaning. In fact it has been reported that $73 \%$ of women experiencing a miscarriage or early loss believed their babies, were babies, whereas 27\% did not (Allen \& Marks, 1993). Gesler (1999) stated that, "we need to listen closely to the language used in medical encounters because it can convey in subtle ways what people are really thinking" (p. 17). With early loss, assumptions cannot be made either way, whether the mother views her baby as a baby or not. By asking what the baby meant to the parents, the provider of care will be able to clarify and be helpful within the meaning context of families.

Many healthcare providers do not know what to say and so they may just say nothing for fear of saying the wrong thing. In one practice situation a woman was admitted for a dilatation and curettage after miscarrying her baby. In practice with this woman, as a student nurse, one of the authors quietly kept accurate charting of blood pressure and the number of peripads soaked with blood. While providing care the mother stopped the author and said,

\section{I don't care about how many pads I have soaked or what my blood pressure is. Do you realize that I have lost $m y$ baby, $m y$ baby? No one acknowledges that this was my baby. Only my husband understands. Even my mother said, 'oh I can have another one.' She doesn't understand and neither do you.}

The author said she was sorry and sat beside this woman and listened to the meaning the baby had for the mother. The mother was very grateful to have someone listen. The lasting lesson for the nurse was that the biomedical assessment was important, so was the woman's own experience of loss.

Terminology familiar to healthcare professionals can be frightening and confusing for persons in the hospital. One author remembers a woman who came to the obstetrical assessment unit as she had not felt her baby move for some time. When the physician used the ultrasound to assess the baby, he stated: "There is no fetal heart." The nurse knew that this meant the baby had died, but the woman was confused and asked, "What do you mean, the baby has no heart? There was a heart there at the other ultrasound, and every time I went to the doctor's office." The nurse had to explain that what the doctor meant was that the baby's heart had stopped beating, not that it was missing. Using inappropriate or perplexing terminology at a time when parents are most in need of clear explanation is not only insensitive, it falls below the expected standard of care.

Asking parents what they are experiencing and what the situation means for them when their baby dies prior to birth and then listening with the intent to understand can be incredibly helpful. It takes courage to be with others as they describe their pain and suffering. Mitchell and Bunkers (2003) described the courage required to jump into the abyss, into the 
realities with people and how the decision to do so, or not, is made in an instant with a knowing that there are consequences to bearing witness and to turning away. A mother's experience of her baby dying prior to birth is an abyss that many wish to avoid as it is unimaginable for many. Listening, without judgment, and bearing witness to the pain is however one of the single most helpful things we can offer parents whose babies die prior to birth.

\section{Theoretical Guides for Practice}

Different theoretical perspectives support a focus in practice on loss and how to be with others living loss. Parse's (1998) practice dimensions: illuminating meaning, synchronizing rhythms, and mobilizing transcendence direct professionals as do the views of Neimeyer $(2000,2001)$ on reconstructing meaning. Another new trend in grief theory is understanding and supporting the continuing bonds that exist after loss rather than demanding the relinquishing of these bonds (Klass, Silverman, \& Nickman, 1996). Focusing on continuing bonds with those who have died directs professionals to explore how parents can continue to have a relationship with the baby who died before birth.

New theoretical understandings of grieving are emerging from research studies and these new views are expanding options for how to expand knowledge and innovate in practice situations. Only one study was found that related the findings of perinatal death to continuing bonds (Wilson, 2001). Here the researcher explored parents' support of their other children after a miscarriage or perinatal death. One of the themes emerging from the study, keeping the baby alive in the family memory, indicated the continuing-bonds perspective. Literature was found describing how the human becoming theory guided research and practice with parents whose babies died prior to birth (Pilkington, 1993, 1999). Interestingly, Pilkington (1993) described a pattern of connecting-separating with the lost baby and how women lived this pattern over time. Listening to parents with the intent to understand their stories, and with the intent to explore the meaning of their baby and the relationship they want to have with the baby is described by many bereaved parents as life-saving. Jordan and Neimeyer (2003) stated that most importantly, "compassionate and empathetic caregivers are needed to provide mourners with a healing experience of being understood and supported in their journey of loss" (p. 780).

New grief theories focusing on meaning reconstruction and continuing bonds and nursing theories, such as human becoming (Parse, 1981, 1998) that focuses on meanings, relationships, and ways of transforming, provide a different language than what Neimeyer (2001) described as "predominantly symptomatic, stress-oriented and pathological" (p. 262). The new language honors the parents'loss in ways consistent with the meanings that the baby holds for them. The new language focuses on meanings, bearing witness, listen- ing, relationships, continuing bonds, rewriting one's story or narrative, hope, living, and transforming with loss.

\section{Mothers' Meanings and Wonderments}

Am I still a mother? What verb tense do I use when I talk about my child? How am I to understand this loss? These are some questions posed by mothers as they live the reality of loss when a baby dies before birth. Answers to the questions, from mothers themselves and from professionals who meet with them, require language that will shape the mother's experience. If there is respect for a continuing bond and relationship after a baby's death then the woman will be seen as mother and dialogue will connect with the meaning that the baby holds for her in the now and in the not-yet. Thus, Mother's Day and the day of the baby's birth may be important, just as they are for any mother who has living children. This is not only significant for healthcare providers to understand but also family and friends, and work colleagues throughout the woman's life. In our experience, mothers often speak of their babies and picture them and what they might be doing in another realm. Mothers ask penetrating questions that leave professionals wondering.

Do we use present tense when we speak of babies who died prior to birth? What do we say if a mother says: "My son is 3 now and I picture him with red curly hair running around with a white tee shirt and little jeans." How are we with these images and the use of present tense? Some people try to tell women whose babies die prior to birth that they are lucky they didn't get to know the child because it would be hard to lose a child that was known. Little is understood about the pain that many parents, siblings, and families experience; the pain of not having any time on earth with this longed-for precious child. In fact the mothers, fathers, and siblings do get to know the child in utero by their unique ways of moving and being. These families, after the death of the baby, create new relationships and new memories in different ways than if the baby had lived.

Finding new ways of connecting with mothers and parents becomes more important when the baby dies before birth. What if healthcare providers asked, "How do you connect with your child now?" or "How old would your son or daughter be?" While a relationship is different, it is nevertheless a relationship. Healthcare providers may consider these points and questions in their care of women and their families whose babies have died.

In a commentary on language used in healthcare entitled, "Watch Your Language," Friedman (2001) took issue with the another term used with the bereaved, achieving closure, a term often used to assess or promote a person's grief resolution. She stated that it is an impossible expectation and we, along with many others, agree that closure is an unattainable, undesirable goal. Friedman explained, 
My concern is that, as people working in healthcare, we can appear callous when we start talking about closure as though we are setting a time limit on the grief of those who have lost people they loved. It's as though we are saying, 'okay; time's up. Get back to normal. In the face of overwhelming loss, things never get back to normal. (p. 9)

Normal is a strange term that can isolate people experiencing loss. Consider the following story.

One woman shared how a psychiatrist asked her if the funeral for her stillborn baby brought closure. The mother recalled her sweet little 6-pound baby boy laying in his white coffin and through tears explained that she felt the funeral honored her baby but exclaimed that it did not bring closure. When the word closure was used she felt as though she had been punched in the stomach; she felt her baby was disregarded, not affirmed and that her grief was belittled. This mother felt as if she was being asked to forget her baby, which she was unprepared to do. She did not return to this psychiatrist.

If mothers and fathers have continuing bonds with their babies that die prior to birth then closure or achieving closure is no longer a goal because relationships with the baby are seen to continue in different ways. So what does this understanding mean for nursing practice? Do we acknowledge the babies who have died prior to birth or skip over them in our care of mothers who have experienced this precious loss? If a woman says, "I have three children, but also one in heaven," what do we say? An elderly woman once said that she "had three children, but really [she] had four." A child who dies is never forgotten. A common phrase in bereavement circles is that grieving is not about forgetting but about remembering. Does this saying also go for parents whose babies die prior to birth? We believe so. What questions do we ask that honor the remembering of a cherished child? We suggest asking what this child means to the mother, father or sibling? Did you name him/her? What is her/his name? How do you acknowledge your child in your life now? What helps you connect to your baby now? Some people express the pain of loss and the continuing bonds of love through art.

\section{The Language of Art}

Samuelson, Radestad, and Segesten (2001) stated in their study with fathers that "the grief after a stillborn child is sometimes described as a neglected or forgotten form of grieving" (pp. 124-125). Could the arts help break the silence and lift the taboo that surrounds speaking of a baby's death? Could more awareness of the deep precious loss of a baby who dies prior to birth be better understood by healthcare professionals and the public through the arts? If we have different understandings and awareness of this experience for mothers, fathers, and families, will we use different language when we speak with them? Will our actions and practices change? Consider the poem written by Carine Blin (2002) to describe the pain 2 days after her son Jacob was born still.
The Pain Two Days After

I feel a big hollow feeling in my empty womb

I feel the silence in my room

Where there should be a tiny, crying voice

I feel the emptiness in my milk-laden, aching breasts

Strapped and bandaged to my rib cage

So that I'll 'dry up' -

But I already feel dried up.

I feel a dull pain in my body

Where Jacob's little body came into the world

But it is nothing next to the gash deep in my soul.

My eyes are swollen with crying

Because my sweet baby boy was born to me

without a breath, without a stir,

Just still, and beautiful, and -

so very still. (p. 23)

Understanding the incredible pain experienced by mothers like Carine will hopefully help healthcare providers choose their language when referring to the baby's death. To refer to Jacob as a stillbirth will be less possible after learning the meaning of this boy to his mother, father, brother, and sisters. He is their precious son/brother who was born still, not an object, not a stillbirth. One woman described to one of the author's that she was leaving the hospital unit with her stillborn daughter in a little white box when a well-meaning healthcare professional said to her encouragingly, "Oh I have seen this all the time, you can have another one." The mother just cried as she walked out the door cradling the cold hard box entombing her precious daughter, while aching and wishing she could carry her baby warm and soft in her arms. Would this healthcare professional say these same words after reading poetry from women whose babies are born still?

The language of loss when a baby dies prior to birth is one that is difficult to describe in words as words can be so limiting in capturing the depth of the experience. As noted above, the arts can help express or language experiences of loss. Seftel (2002) is an artist and art therapist who began "The Secret Club Project," an art exhibit where she invited women who experienced the loss of an infant prior to birth to submit their artistic expressions of the meaning of their loss. Seftel, who experienced the loss of her own baby through miscarriage, displays one of her pieces in the exhibit. She described her painting in the following way, "this piece remains beyond spoken language for me. I was never able to title it" (Seftel, I11). In wondering if "others were using art to express their pain, confusion, anger and isolation following their own losses" (Seftel, I11), the seeds for this exhibit were sown. Other women shared their artful expressions of loss through sculpture, drawings, computer art, photography, ceramics, printmaking and blown glassworks. One artist (Carver, 2005) explained that "through art [she was] able to speak of an expe- 
rience which is unspeakable, and therefore unknown." Seftel (2002) hoped that more people would better understand women's profound experiences of loss through the art exhibit. The exhibit gave voice to the women's experiences but also helps lift the taboo of this hidden topic by sharing the secret with others. The power of the artwork, which can be experienced on exhibit over the Internet or brought directly to your area of the world, can help shift understanding and that may help humanize the language of loss when an infant dies prior to birth.

Another incredible example of how art helps people to language the loss of a baby born still can be found in a book entitled The Anguish of Loss (Fritsch \& Ilse, 1992). Through poetry and sculpture one is deeply moved to understand the painful experience of loss experienced by a mother and father when their much loved baby is born still. Beyond sharing the secret with society and breaking the silence we believe the arts have a role to play in healthcare education as powerful vehicles for enhancing understanding of the experience of loss of families whose babies die prior to birth.

To conclude, we must emphasize once again that we do not believe healthcare professionals intend to harm or add to parents suffering when they use objectifying biomedical language when a baby dies prior to birth. Nor do we believe that the words healthcare professionals, family, friends and colleagues use to try and diminish the loss of the baby intend to harm the parents. What we do believe is that language that honors and affirms a baby who dies prior to birth, consistent with the parents' meaning of this baby, will enhance the parents health, quality of life, and grieving experience. We hope that this column has provided opportunities for reflection on the language used when a baby dies prior to birth. We further hope that healthcare professionals become more aware of the meanings of language; how unnecessary suffering for those who already suffer greatly can be diminished; and how health, quality of life, and the experience of grieving a loss can be enhanced.

\section{References}

Allen, M., \& Marks, S. (1993). Miscarriage: Women sharing from the heart. New York: John Wiley \& Sons, Inc.

Blin, C. (2002). The pain two days after. In Perinatal Bereavement Services Ontario, 10th anniversary memory collection (p. 23). Markham, Ontario: Perinatal Bereavement Services Ontario.

Carver, M. (2005). [Quote on website homepage]. Retrieved January 9, 2005, from The Secret Club Project Web site: http:// www.secretclubproject.org/home.html

Chalmers, B. (1992). Terminology used in early pregnancy loss. British Journal of Obstetrics \& Gynecology, 99, 357- 358.

Friedman, E. (2001). Watch your language. Health Forum Journal, 44(3), 8-10.

Fritsch, J., \& Ilse S. (1992). The anguish of loss (2nd ed.). Maple Plain, MN: Wintergreen Press.

Gesler, W. M. (1999). Words in wards: Language, health and place. Health \& Place, 5(1), 13-25.
Hazen, M. A. (2003). Societal and workplace responses to perinatal loss: Disenfranchised grief or healing connection. Human Relations, 56(2), 147-166.

Hutchon, D. J. R. (1998). Understanding miscarriage or insensitive abortion: Time for more defined terminology? American Journal of Obstetrics \& Gynecology, 179, 397-398.

International Stillbirth Alliance. (2004). Know the facts. Retrieved November 30, 2004, from http://www.stillbirthalliance.org/ index.cfm.

Jordan, J. R., \& Neimeyer, R. A. (2003). Does grief counseling work? Death Studies, 27, 756-786.

Klass, D., Silverman, P. R., \& Nickman, S. L. (1996). Continuing bonds: New understandings of grief. Washington, DC: Taylor \& Francis.

Kolker, A., \& Burke, B. M. (1993). Grieving the wanted child: Ramifications of abortion after prenatal diagnosis of abnormality. Health Care for Women International, 14, 513-526.

Leon, I. G. (1992). The psychoanalytic conceptualization of perinatal loss: A multidimensional model. American Journal of Psychiatry, 149(11), 1464-1472.

Mitchell, G. J., \& Bunkers, S. S. (2003). Engaging the abyss: A mistake of opportunity? Nursing Science Quarterly, 16, 121-125.

Neimeyer, R. A. (2000). Searching for the meaning of meaning: Grief therapy and the process of reconstruction. Death Studies, 246, 541-558.

Neimeyer, R. A. (2001). Meaning reconstruction and the experience of loss. Washington, DC: American Psychological Association.

Parse, R. R. (1981). Man-living-health: A theory of nursing. New York: Wiley.

Parse, R. R. (1998). The human becoming school of thought: A perspective for nurses and other health professionals. Thousand Oaks, CA: Sage.

Parse, R. R. (2002). Words, words, words: Meanings, meanings, meanings! Nursing Science Quarterly, 15, 183.

Pilkington F. B. (1993). The lived experience of grieving the loss of an important other. Nursing Science Quarterly, 6, 130-139.

Pilkington F. B. (1999). An ethical framework for nursing practice: Parse's human becoming theory. Nursing Science Quarterly, 12, 21-25.

Pridjian, G., \& Moawad, A. H. (1989). Missed abortion: Still appropriate terminology? American Journal of Obstetrics \& Gynecology, 161, 261-262.

Rosato, W. S. (Producer). (2004). ER [Television series]. California: NBC.

Samuelsson, M., Radestad, I., \& Segesten, K. (2001). A waste of life: Father's experience of losing a child before birth. BIRTH, 28, 124-130.

Scott, J. R., Gibbs, R. S., Karlan, B. Y., \& Haney, A. F. (2003). Danforth's obstetrics and gynecology (9th ed.). Philadelphia: Lippincott Williams and Wilkins.

Seftel, L. (2002). [Description of an untitled painting]. Retrieved November 30, 2004, from The Secret Club Project Web site: http://www.secretclubproject.org/artist_lseftel.html

Statistics Canada. (2003). Stillbirths. The Daily. Retrieved November 30, 2004, from http://www.statcan.ca/Daily/English/ 030811/d030811b.htm

Williams, G. B. (2001). Short-term grief after an elective abortion. Journal of Obstetrics, Gynecologic and Neonatal Nursing, 30 , 174-183.

Wilson, R. E. (2001). Parents' support of their other children after a miscarriage or perinatal death. Early Human Development, 61, 55-65. 